\title{
Centrifuge modelling of breaking waves and seashore ground
}

\section{Hidenori Takahashi PhD}

Head of Group, Soil Stabilization Group, Geotechnical Engineering Division, Port and Airport Research Institute, MPAT, Yokosuka, Japan (corresponding author: takahashi-h@pari.go.jp) (Orcid:0000-0001-7427-6200)

\section{Yoshiyuki Morikawa PhD}

Director of Division, Geotechnical Engineering Division, Port and Airport Research Institute, MPAT, Yokosuka, Japan

\author{
Hiroaki Kashima PhD \\ Deputy Director, Ports and Harbours Bureau, Ministry of Land, \\ Infrastructure, Transport and Tourism, Tokyo, Japan (Formerly of Coastal \\ and Ocean Engineering Division, Port and Airport Research Institute, MPAT)
}

Seashore ground stability is a crucial issue in the composite problems of hydraulics and geotechnics. Many studies have been conducted on covering materials and sediment transport. However, very few studies have examined this issue from a geotechnical viewpoint. This is because the ground displays complicated responses against breaking waves, and because it is difficult to examine ground behaviours through a prototype-scale model test. The physical modelling of breaking wind waves and seashore ground helps explain ground stability. This study examined the efficacy of centrifuge modelling with regard to this issue. The authors showed the similarity laws, including fluid behaviours and developed a new wave generator. The centrifuge model efficacy was verified mainly by way of the modelling of model tests on waveform, wave height and water pressure on and in the ground. Additional tests indicated that excess pore-water pressure was generated due to wave set-up. Increasing the wave height and/or wave frequency caused a seepage force, which could decrease ground stability.

\section{Notation}

D

$d$

$d_{\mathrm{d}}$

$d_{\mathrm{h}}$

e

Fr

g

$H$

$H_{0}$

$h$

$i$

$K_{\mathrm{s}}$

$k$

$L$ diameter of soil particle

displacement

depth from ground surface

horizontal distance from seashore

half-amplitude of displacement of wave plate

Froude number

gravitational acceleration

wave height

deep-water wave height

water depth

hydraulic gradient

shoaling coefficient

wave number

representative length and wave length

deep-water wave length

reduction ratio of the model

wave period

time

representative velocity

water pressure

flow velocity

mean flow velocity

angle of sea-bottom slope

strain

excess water and pore-water pressure

dynamic viscosity

density

stress

\section{Introduction}

Breaking wind waves affect the stability of seashore ground consisting of sand and gravel. This is an important composite problem in hydraulics and geotechnics (Figure 1). Several studies have focused on related issues and many researchers examined the stability of covering plates and rubbles protecting the seashore, by using analytical methods and hydraulic model tests in a gravitational field (e.g. Andersen and Burcharth, 2010; Hall and Kao, 1991; Van Der Meer, 1987). Several studies have also been conducted on sediment transport. To study ground response and liquefaction under water caused by waves, numerical modelling and hydraulic model tests have also been performed (e.g. Chang et al., 2007; Madsen, 1978; Seed and Rahman, 1978; Sekiguchi et al., 1995; Tsai and Lee, 1995). However, the scope of these studies was limited to problems occurring in the shallow part or to a fraction of the seashore ground.

Grant (1948) indicated that seashore erosion was strongly related to ground water level. This was followed by studies proposing several countermeasures against erosion, such as a pumping system and permeable layer embedded in the ground (e.g. Chappell et al., 1979; Davis et al., 1992; Machemehl et al., 1975). Elfrink and Baldock (2002) and Bakhtyar et al. (2009) summarised the studies on sediment transport in the swash zone. They also noted that it was important to consider ground water level. These studies were crucial in demonstrating that ground states, such as stress, pore-water pressure and water flow, enable the detection of seashore ground stability. 
International Journal of Physical Modelling in Geotechnics Volume 19 Issue 3
Centrifuge modelling of breaking waves

and seashore ground

Takahashi, Morikawa and Kashima

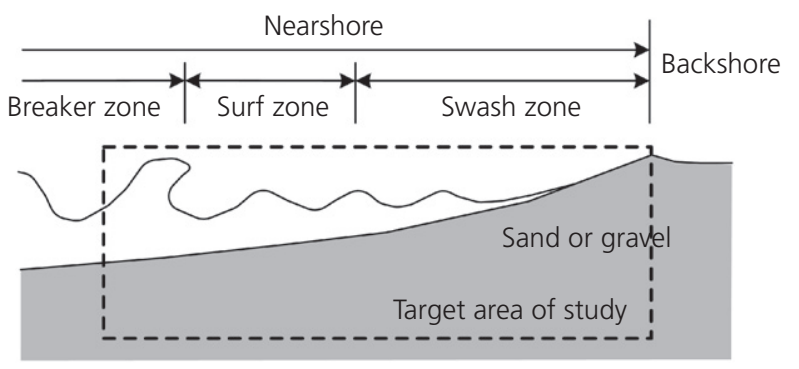

Figure 1. Conceptual diagram of seashore and targeted area

However, limited attention has been directed towards examining ground states. This is because the ground displays complicated responses against breaking waves, and because it is difficult to examine ground behaviours through a prototypescale model test. Seashore ground includes an unsaturated area, which has not been studied yet. For this reason, the application of analytical approaches was difficult. Comprehending the seashore ground state will help explain ground stability.

Model tests in gravitational fields generally utilise a reduced scale model, which has some shortcomings; namely, it is difficult to reproduce prototype stress and water pressure in a reduced scale model. Additionally, when using a large-scale model, considerable effort is required to implement a series of tests. To overcome these shortcomings, the authors introduced a centrifuge test technique. The centrifuge test uses a small model, which can produce large ground stress, pore-water pressure and water pressure corresponding to those of a prototype model. The test is effective for parametric study, since small-sized models can be easily manufactured. Several previous studies examined ground responses by using a centrifuge test (Baba et al., 2002; Cheng, 2003; Gao and Randolph, 2005; Phillips and Sekiguchi, 1992; Sassa and Sekiguchi, 1999; Sekiguchi and Phillips, 1991; Sekiguchi et al., 1995; Takahashi et al., 2010). The studies conducted by Sekiguchi and Phillips (1991) and Phillips and Sekiguchi (1992) were especially innovative because the wave-propagation test was first conducted in a centrifuge. Sekiguchi et al. (1995) and Sassa and Sekiguchi (1999) used a centrifuge to investigate the ground's response and liquefaction phenomenon under progressive waves. Baba et al. (2002) introduced a plunger-type wave generator for a drum-type centrifuge. They also examined fundamental wave properties and ground responses at a caisson-type breakwater. However, these studies did not consider breaking waves and seashore ground behaviour. Additionally, the efficacy of the centrifuge model test has not been examined in detail. Although Takahashi et al. (2010) examined near-shore ground responses, they did not discuss the similarity law and efficacy of the centrifuge model. The similarity law and centrifuge model efficacy must be clarified in order to examine ground behaviour under breaking waves.

This study demonstrates the efficacy of the breaking waves centrifuge model and seashore ground affected by wind waves in the following ways: first, the study showed the similarity laws including fluid behaviours; second, a new wave generator was developed, which accounts for limited capacity and centrifuge platform area. Third, the modelling of models method, numerical analysis and theoretical and empirical equations were employed in order to investigate the reproducibility of breaking waves and ground responses on pore-water pressure. Finally, this study examined the variation properties of ground pore-water pressure. Fluid behaviours and pore-water pressure are extremely important in terms of ground stability, since they determine the stress conditions.

\section{Similarity laws and development of wave generator}

\subsection{Similarity laws}

Soil has a non-linear stress-strain relationship; therefore, the centrifuge technique is an effective measure for understanding deformation and ground failure behaviours, since centrifuge can make a prototype of stress and strain conditions. The efficacy of centrifuge has been demonstrated by many researchers (e.g. Tayler, 1995). Bezuijen and Steedman (2010) and Takahashi et al. (2014) summarised the similarity laws on the propagation of excess pore-water pressure in a centrifuge. Table 1 lists the similarity laws, which are ratios, in cases where water and viscous fluid are used in the model. $N$ indicates the reduction ratio of the model size; the centrifugal acceleration is denoted by $N \boldsymbol{g}$. The similitude time ratio is $1 / N$, when the two conditions represented by shading in the table, namely turbulent flow of water with $1 / N$ soil particle size (law 1) and laminar flow of viscous fluid with $1 / 1$ soil particle size, are considered (law 3). The latter condition, law 3, is often used for the centrifuge model test of liquefaction (e.g. Takahashi et al., 2006). The present study used the former condition, which is expressed by law 1 .

Fluid behaviour, such as wave propagation and non-linear deformation, follows Froude's law. The ratio of the model scale $N$ was set to $18-30$. This was sufficiently small not to account for the viscous force and surface tension against the inertia force. The Froude number Fr must remain constant in a hydraulic model test, in order to simulate the fluid behaviour dominated by gravity, as indicated by the following formula

1. $\operatorname{Fr}=\frac{U}{\sqrt{L g}}$ 


\begin{tabular}{|c|c|c|c|c|c|}
\hline \multirow[b]{4}{*}{ Items } & & \multirow[b]{4}{*}{ Prototype } & \multicolumn{3}{|c|}{ Model (in centrifuge) } \\
\hline & & & Law 1 & Law 2 & Law 3 \\
\hline & & & \multicolumn{2}{|c|}{ Water } & Viscous fluid \\
\hline & & & Small particle & Pro & particle \\
\hline \multirow[t]{5}{*}{ Test conditions } & Centrifugal acceleration, $\boldsymbol{g}$ & 1 & N & N & N \\
\hline & Model length, $L$ & 1 & $1 / N$ & $1 / N$ & $1 / N$ \\
\hline & Diameter of soil particle, $D$ & 1 & $1 / N$ & 1 & 1 \\
\hline & Density, $\rho$ & 1 & 1 & 1 & 1 \\
\hline & Dynamic viscosity, $v$ & 1 & 1 & 1 & $N$ \\
\hline \multirow[t]{4}{*}{ Ground responses } & Water pressure, $u$, and stress, $\sigma$ & 1 & 1 & 1 & 1 \\
\hline & Hydraulic gradient, $i$ & 1 & 1 & 1 & 1 \\
\hline & Displacement, $d$ & 1 & $1 / N$ & $1 / N$ & $1 / N$ \\
\hline & Strain, $\varepsilon$ & 1 & 1 & 1 & 1 \\
\hline \multirow[t]{2}{*}{ Laminar } & Mean flow velocity, $\bar{v}$ & 1 & $1 / \mathrm{N}$ & $N$ & 1 \\
\hline & Time of seepage, $t$ & 1 & 1 & $1 / N^{2}$ & $1 / N$ \\
\hline \multirow{2}{*}{ Turbulent } & Mean flow velocity, $\bar{v}$ & 1 & 1 & $N^{1 / 2}$ & $N^{1 / 2}$ \\
\hline & Time of seepage, $t$ & 1 & $1 / N$ & $1 / N^{3 / 2}$ & $1 / N^{3 / 2}$ \\
\hline
\end{tabular}

Similitude ratios of time are $1 / N$ in the shaded conditions

where $U$ is the representative velocity $(\mathrm{m} / \mathrm{s}), L$ the representative length $(\mathrm{m})$ and $\boldsymbol{g}$ is the gravitational acceleration $\left(\mathrm{m} / \mathrm{s}^{2}\right)$. $U$ is constant, since $g$ and $L$ are multiplied by $N$ and $1 / N$ and offset in the centrifuge. Most of the fluid behaviours are dependent on flow velocity; therefore, its reproduction is an important advantage of the centrifuge model test. Since the similitude time ratio for fluid behaviours is $1 / N$, the similitude time ratio for ground behaviours must be $1 / N$. As mentioned previously, the similitude time ratio on the propagation of excess pore-water pressure in the ground could also equal $1 / N$, under certain conditions.

Other phenomena, such as seashore erosion, could not be explained by the above similarity laws alone and were not considered here. Erosion might affect fluid behaviours. The size of the model is relatively small in the centrifuge model test and indicates that the wave's splash and air bubbles cannot be reproduced accurately, and that the sensor's size might affect test results.

\subsection{Development of wave generator}

In a centrifuge, the space and electric capacity of the platform are usually limited. Hence, it is important to design a compact wave generator, which can be moved by a small electric motor. In a hydraulic model test, in a gravitational field, a piston-type wave generator is often used, in which the plate is moved by a motor attached above a specimen container. In this type, a wave-making plate should be firmly fixed in the direction perpendicular to the wave-propagation direction. This indicates that this type of a wave generator requires heavy moving parts and a large amount of electricity to move them. This problem was solved by Sekiguchi et al. (1995) by using a flap-type wave generator, wherein the use of a hinge at the bottom of a plate causes the plate to swing. Baba et al. (2002) used a plungertype wave generator, in which a float was repeatedly pushed into the water and then pulled. However, these wave generators are unable to move water in deep areas, and are unsuitable to producing shallow water waves.

In this study, a new piston-type wave generator for a centrifuge model test was developed. In this apparatus, the use of the cam mechanism moved a wave-making plate joined to a motor placed outside the specimen container through a waterproof hole on the side wall (Figure 2). The wave generator was unable to produce random waves. However, it was relatively simple, compact and suitable to centrifuge model testing since it did not require large space or electricity. The developed wave generator could move horizontally with a maximum frequency of $5 \mathrm{~Hz}$ and maximum amplitude of $50 \mathrm{~mm}$. On prototype scale, when the test model was subjected to centrifugal acceleration of $30 \mathrm{~g}$, it moved with a frequency of $0 \cdot 167 \mathrm{~Hz}$ and amplitude of $1.5 \mathrm{~m}$.

\section{Modelling of models tests of specimen without ground}

\subsection{Model test conditions}

Prior to examining the efficacy of a centrifuge model test on breaking waves and seashore ground response, a sinusoidal wave was generated in a specimen container with no seashore ground. The machine used in the study was PARI Mark II, 


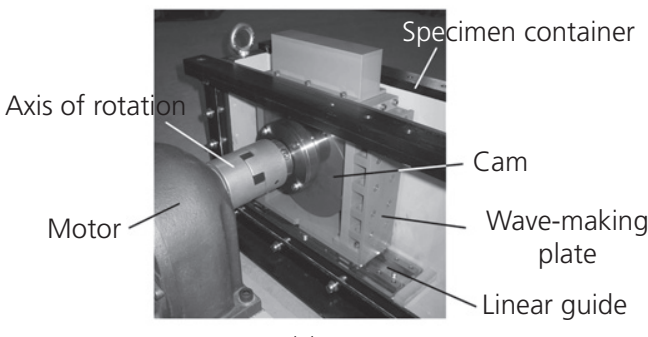

(a)

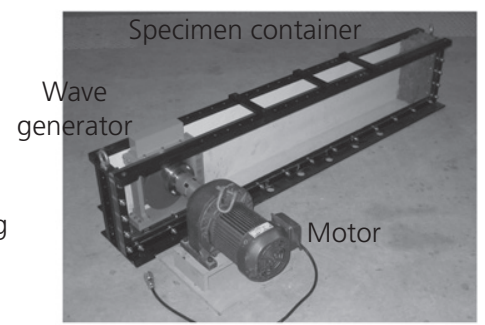

(b)

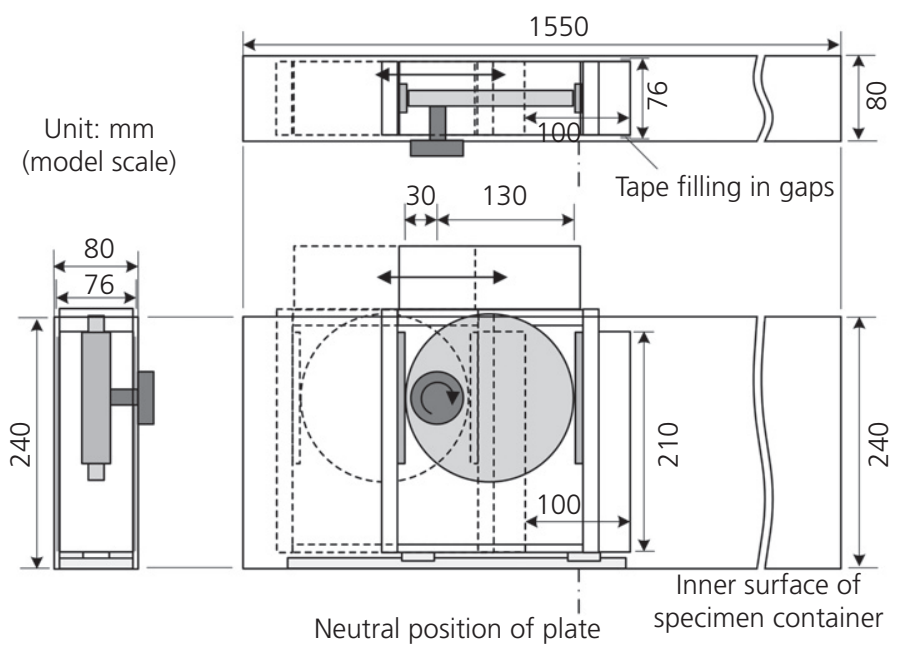

(c)

Figure 2. Wave generator used in the model tests: (a) wave generator, (b) entire equipment, (c) sectional diagram

developed by the Port and Airport Research Institute (Kitazume and Miyajima, 1995). The machine had a large platform, which could accommodate a specimen container with a maximum length of $1600 \mathrm{~mm}$. Waves progressed in a direction perpendicular to the plane of rotation. This indicated that it was not necessary to consider the Coriolis force effect (e.g. Tayler, 1995).

The 'modelling of models' method investigated the reproducibility of these waves in a prototype. This method is often used to examine the effectiveness of a centrifuge test (e.g. Tayler, 1995). In this method, the same prototype is modelled by various models, at different scales, and the results are compared to confirm whether they coincide. Figure 3 shows the conceptual diagram of this method. Advantages of this method include using the same test conditions, such as soil type, sedimentary states and apparatus, in various models, and thereby exclude effects other than centrifugal acceleration.

Two test series were carried out with different water levels and centrifugal accelerations. Table 2 displays the list of tests. Figure 4 describes the schematic model views. The

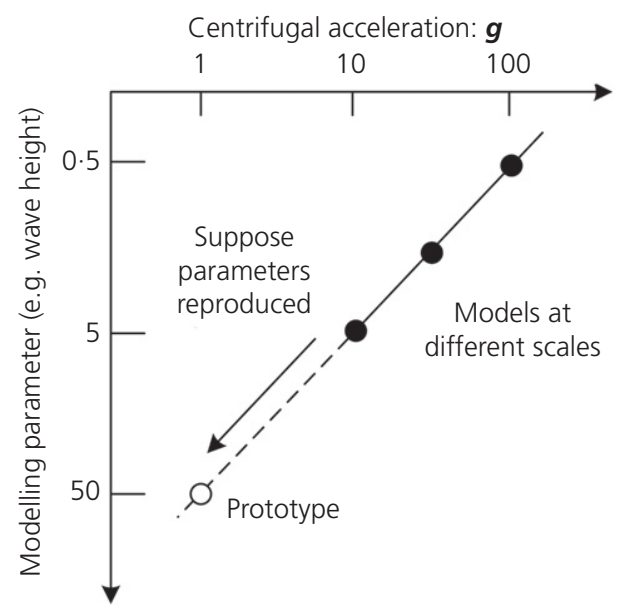

Figure 3. Conceptual diagram of the modelling of models method

multiplication of the model scale and amplification of centrifugal acceleration became 1 in each series, except for N2-20A. This indicated that those cases modelled the same prototype. 
Table 2. List of model tests (series N1 and N2)

\begin{tabular}{|c|c|c|c|c|c|c|}
\hline Series & Case & $\begin{array}{c}\text { Centrifugal } \\
\text { acceleration: } g\end{array}$ & Water depth: $\mathbf{m m}$ & $\begin{array}{l}\text { Longitudinal } \\
\text { length: } \mathrm{mm}\end{array}$ & $\begin{array}{l}\text { Displacement of } \\
\text { wave plate: } \mathrm{mm}\end{array}$ & $\begin{array}{l}\text { Frequency of } \\
\text { wave plate: } \mathrm{Hz}\end{array}$ \\
\hline \multirow[t]{2}{*}{ N1 } & N1-18 & 18 & 150 & 1230 & \pm 50 & 3.00 \\
\hline & $\mathrm{N} 1-30$ & 30 & 90 & 740 & \pm 30 & 5.00 \\
\hline \multirow[t]{3}{*}{ N2 } & $\mathrm{N} 2-20$ & 20 & 150 & 1230 & \pm 30 & $3 \cdot 33$ \\
\hline & N2-30 & 30 & 100 & 820 & \pm 20 & 5.00 \\
\hline & N2-20A & 30 & 150 & 1230 & \pm 30 & $3 \cdot 33$ \\
\hline
\end{tabular}

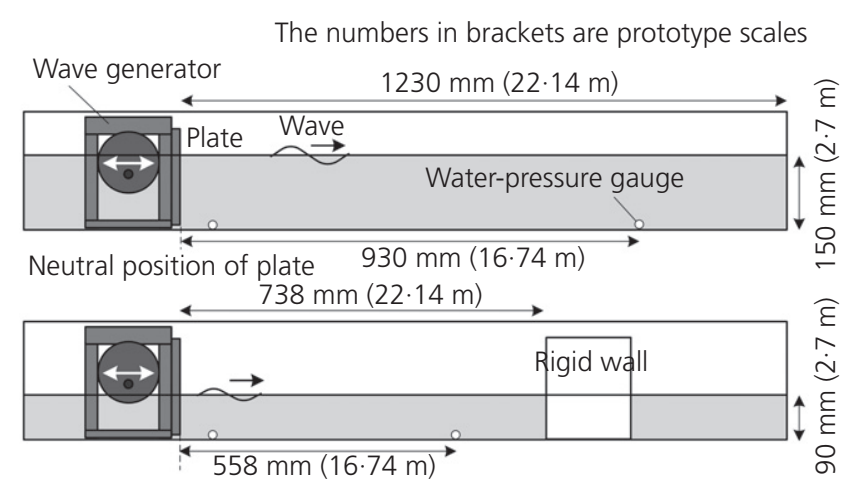

(a)
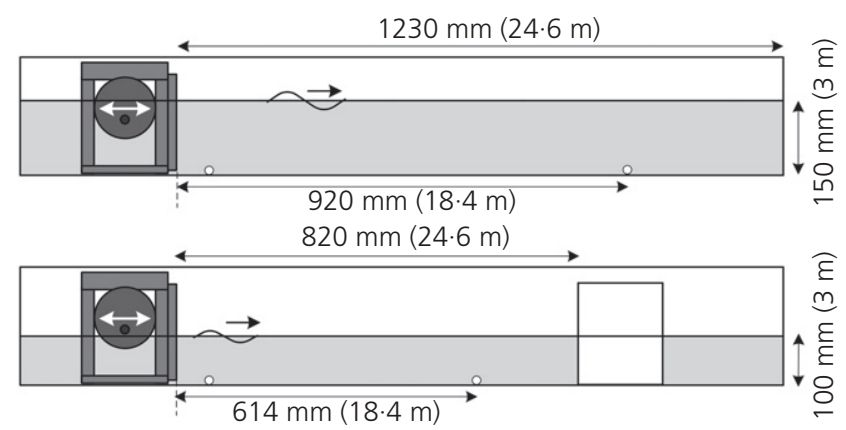

(b)

Figure 4. Schematic views of the models (series N1 and N2): (a) series N1 (upper: N1-18, lower: N1-30), (b) series N2 (upper: N2-20, N2-20A; lower: N2-30)

Case N2-20A did not purposely satisfy the similarity law by increasing centrifugal acceleration. Water-pressure gauges were placed at the bottom of a specimen container, as shown in Figure 4 . The pore-water pressure gauge used for the tests had high responsivity for a dynamic test. A metal mesh filter was attached on the diaphragm in order to avoid soil contact. The sensors were manufactured by SSK Co, in Japan, and the type and capacity of the diaphragm were silicon strain gauge and $50-200 \mathrm{kN} / \mathrm{m}^{2}$, respectively. Natural water, without special viscosity, was used. The specimen container was fixed to the platform of a centrifuge machine. A certain centrifugal acceleration was added to the model, and waveform and water pressure were observed during operating the wave generator. In order to capture the waveform, a $\boldsymbol{g}$-proof high-speed camera was attached to the platform beside the specimen container. Since the wave period was short $(0 \cdot 2-0 \cdot 33 \mathrm{~s})$, a high-speed camera was required. The capture speed and resolution of the camera were set to $1000 \mathrm{fps}$ and $1280 \times 1024$ pixels, respectively.

\subsection{Waveform}

Waveforms captured by a high-speed camera were compared to confirm waveform similarity. Figure 5 shows the waveforms observed in cases N1-18 (under 18g) and N1-30 (under 30g). The pictures were captured by each $1 / 4$ period. Picture sizes were adjusted to the same scale, in order to compare them visually. A part of case N1-18 was invisible due to the camera's small viewing angle. Water surfaces were traced by broken lines in order to identify them easily.

Waves were reflected at the end wall of the specimen container, and a part of the reflected waves was reflected on the wavemaking plate. Gaps existed between the wave-making plate and the side wall of the specimen container. These gaps were $2 \mathrm{~mm}$ at both sides of the plate. A part of the reflected waves penetrated the gaps. As shown in Figure 5, the waveforms at the 0/4 period, of both test cases, had an upsurge and downturn on the left and right sides, respectively. They also had a downturn and upsurge on the left and right sides at the 2/4 period, respectively. Thus, the waveforms in N1-18 and N1-30 coincided well. Although the pictures captured in N2-20 and N2-30 are not shown here for the sake of brevity, the waveforms in N2-20 and N2-30 also coincided with each other.

In addition to the modelling of models tests, fluid numerical analysis, on prototype scale, was also carried to present the efficacy of the centrifuge model test. The high accuracy of fluid numerical analysis is widely known; hence, prototype motion estimated by the modelling of models tests was compared to the one estimated by numerical analysis. The program code used in this study was CADMAS-SURF, which was developed by collaboration between researchers and has already been applied to designs in several fields (CDIT, 2001). This code utilises the Navier-Stokes equation, continuity 
International Journal of Physical Modelling in Geotechnics Volume 19 Issue 3
Centrifuge modelling of breaking waves and seashore ground

Takahashi, Morikawa and Kashima

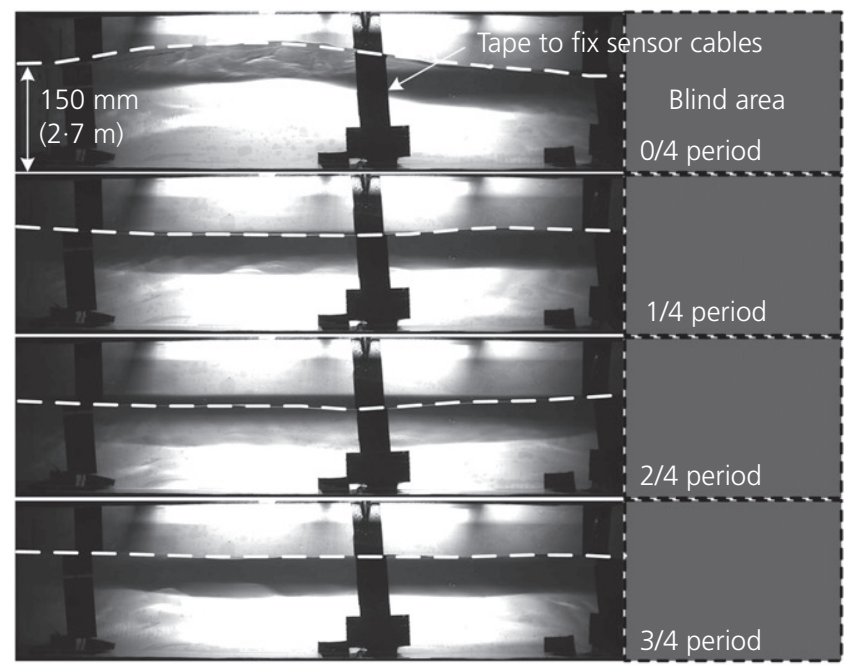

(a)

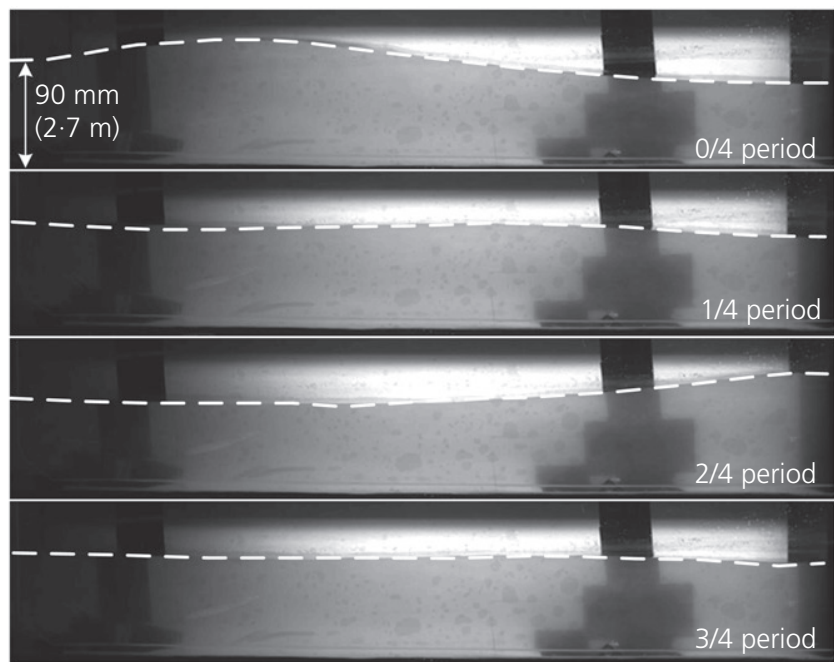

(b)

Figure 5. Waveforms observed in the tests (cases N1-18 and N1-30): (a) case N1-18 (under 18g), (b) case N1-30 (under 30g)

equations, and the volume of fluid (VOF) method by Hirt and Nichols (1981), in order to calculate the fluid's movement and free surface. Various methods were incorporated into the code in order to handle non-linearity, wave breaking and air bubbles in breaking waves. Many researchers have demonstrated the high accuracy of this program (e.g. Hanzawa et al., 2012; Phung et al., 2004; Sakuraba et al., 2008).

Numerical analysis simulated series $\mathrm{N} 1$ by converting it to the prototype. The mesh width was set as $0.25 \mathrm{~m}$ in the horizontal direction, and $0.10 \mathrm{~m}$ in the vertical direction. The width of the rightmost mesh was changed to $0 \cdot 14 \mathrm{~m}$, since the total longitudinal length of the calculated area was $22 \cdot 14 \mathrm{~m}$. The piston-type wave-generator scheme, prepared in the program code, was used to input the waves. The wave period was $6 \cdot 0 \mathrm{~s}$. The wave height was $1.04 \mathrm{~m}$ and was calculated by the following equation

2. $\frac{H}{2 e}=\frac{4 \sinh ^{2}(2 \pi h / L)}{4 \pi h / L+\sinh (4 \pi h / L)}$

where $H$ is the wave height $(\mathrm{m}), e$ the half-amplitude of waveplate displacement $(\mathrm{m}), h$ the water depth $(\mathrm{m})$ and $L$ is the wave length given by the linear dispersion relationship. A wave attenuation area with a width of $4.0 \mathrm{~m}$ was set on the side of the wave source. Although details are provided in the next section, the width of the area was determined such that the waves became stable. Figure 6 presents the calculated waveforms of each $1 / 4$ period. These waveforms were found to correspond to the results shown in Figure 5.

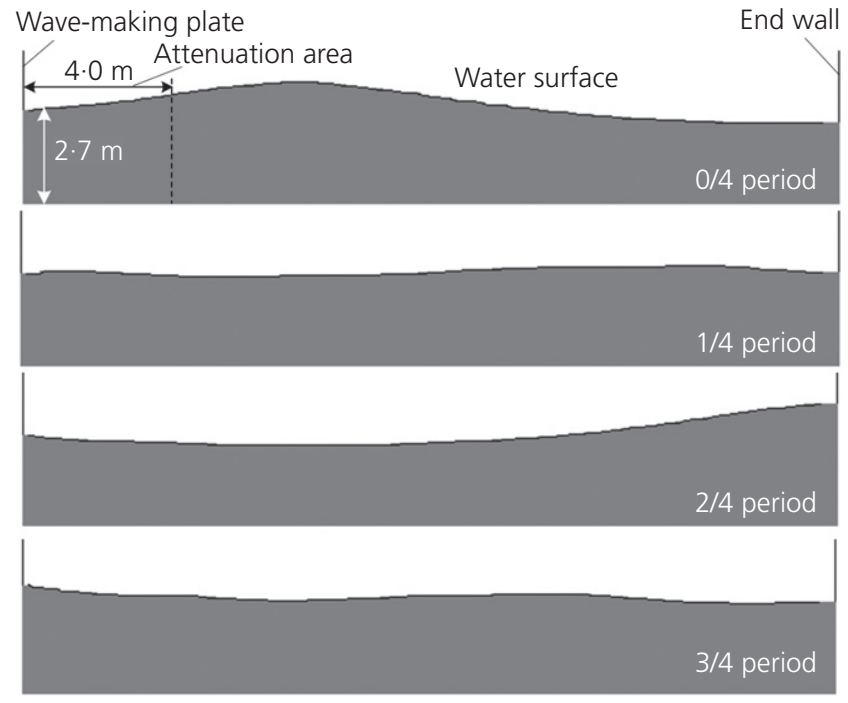

Figure 6. Calculated waveforms simulating series N1

\subsection{Water pressure}

Figure 7 shows the variations of excess water pressures, measured at the bottom, in series N1 and N2. Time is converted to the prototype. Both variations were found to coincide well when the similarity laws were satisfied. On the other hand, case N2-20A, which did not satisfy the similarity law, had different excess water pressure. This indicated that centrifugal acceleration was important in prototype simulation. Thus, the efficacy of the centrifuge model test was verified on the point of water pressure. 
International Journal of Physical Modelling in Geotechnics Volume 19 Issue 3
Centrifuge modelling of breaking waves

and seashore ground

Takahashi, Morikawa and Kashima

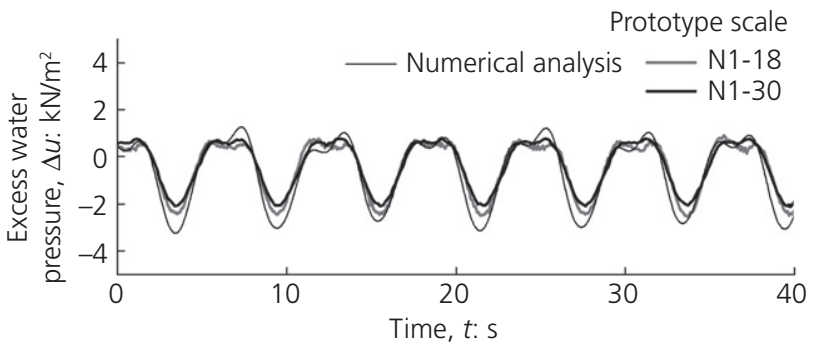

(a)

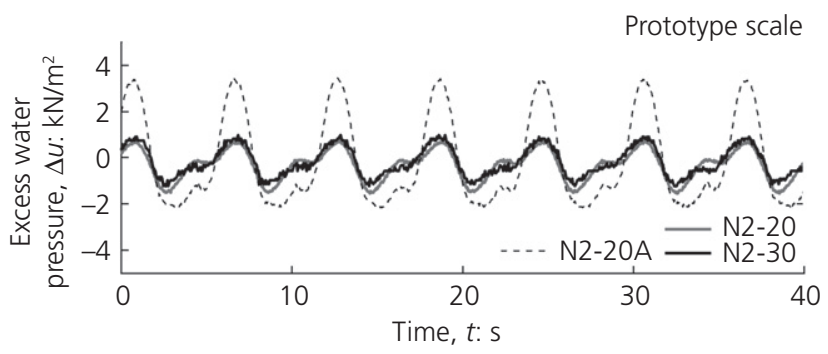

(b)

Figure 7. Experimental and calculated variations of water pressure (series N1 and N2): (a) series N1 (16.7 m from wave plate on prototype scale), (b) series N2 (18.5 m from wave plate on prototype scale)

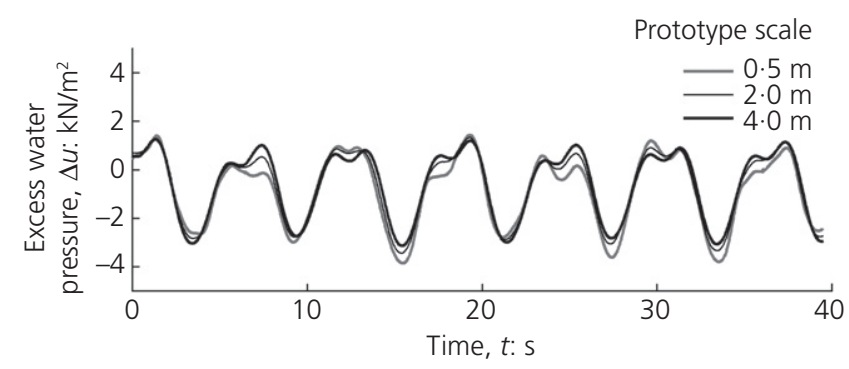

Figure 8. Calculated variations of water pressure when changing width of attenuation area

The test results, with respect to water pressure, were also compared to those of numerical analysis. The effect of wave attenuation was investigated prior to simulating the tests. Figure 8 shows the calculated variations of water pressures and assumes series N1 by changing the width of the wave-attenuation area. In the small-width case, variation was unstable. In contrast, the variation became stable and the amplitude was constant in the case where the width was $4.0 \mathrm{~m}$. Figure 7(a) includes the results calculated with an attenuation width of $4.0 \mathrm{~m}$. The model test and numerical analysis results were similar. The amplitude difference was approximately $10-30 \%$. This fact demonstrates the efficacy of the centrifuge model test on wave propagation, in the specimen container with no seashore ground.

\section{Modelling of models tests of specimen with seashore ground}

\subsection{Model test conditions}

The test series S1, which arranged the seashore ground, was used to investigate the efficacy of a centrifuge model test on breaking waves and ground response on pore-water pressure. Their reproducibility in a prototype was examined by the modelling of models method. Four test cases were carried out by changing the centrifugal acceleration and ground material. Table 3 and Figure 9 show the conditions and schematic views of these cases, respectively. Cases S1-20 and S1-30 were used to confirm the prototype similarity. Cases S1-20Sn and S1-20Gr purposely had the ground materials, which did not satisfy the similitude ratio.

The model tests used four materials: number 2 Soma sand for case S1-20, number 3 Soma sand for case S1-30, number 7 Iide sand for case S1-20Sn and gravel for case S1-20Gr. Soma and Iide sands were silica sands excavated in the Fukushima and Yamagata prefectures in Japan, respectively. Gravel was gathered from a river. The two types of Soma sands had similar particle shapes and diameters of approximately $2 \cdot 0-3 \cdot 2 \mathrm{~mm}(20 \mathrm{~g}$ test) and $1 \cdot 0-2 \cdot 5 \mathrm{~mm}(30 \mathrm{~g}$ test). The diameter ratios of these sands were almost $3: 2$, which corresponded to the reduction ratio of model size. Since the diameters of Soma sand particles were large, the water flow in the void was considered as turbulent in cases S1-20 and S1-30. Natural water without special viscosity was used in the test. The conditions indicated that, based on the similarity law shown in Table 1 as law 1, the prototype seashore consisted of rubble with a diameter of $60 \mathrm{~mm}$. Iide sand had a much smaller particle diameter than Soma sand, and gravel had a much larger diameter than Soma sand. Their diameters were approximately 0.09-0.43 and 3-7 $\mathrm{mm}$, respectively.

The ground was manufactured by soft tapping layer by layer. An exception to this was the case of S1-20Sn, where the ground was made by the sand-raining technique (e.g. Takahashi et al., 2006). Each method was chosen in terms of easiness to control ground density. As shown in Figure 9, the models had two slopes: the steep slope near a wave generator could reduce the space used in the specimen container, while the gentle slope modelled a general seashore. Water-pressure gauges were put on and in the model. In the case of S1-20Gr, in order to measure flow velocity, two sensors were put on at the same place on the ground surface, in two directions; namely, in the same direction as the wave generator plate, and in the direction perpendicular to the wave generator plate. The head calculated by the sensor facing the wave-making plate included the velocity head. The flow velocity could be calculated by the difference between the values measured by the two sensors, based on Bernoulli's law. After making the ground 
Table 3. List of model tests (series S1)

\begin{tabular}{|c|c|c|c|c|c|c|c|}
\hline Series & Case & $\begin{array}{l}\text { Centrifugal } \\
\text { acceleration: } g\end{array}$ & $\begin{array}{l}\text { Water depth: } \\
\text { mm }\end{array}$ & $\begin{array}{l}\text { Longitudinal } \\
\text { length: } \mathrm{mm}\end{array}$ & $\begin{array}{l}\text { Displacement of } \\
\text { wave plate: } \mathrm{mm}\end{array}$ & $\begin{array}{c}\text { Frequency of } \\
\text { wave plate: } \mathrm{Hz}\end{array}$ & $\begin{array}{l}\text { Average diameter } \\
\text { of soil particle: } \\
\text { mm }\end{array}$ \\
\hline \multirow[t]{4}{*}{ S1 } & S1-20 & 20 & 150 & 1230 & \pm 30 & $3 \cdot 33$ & $2 \cdot 0-3 \cdot 2$ \\
\hline & S1-30 & 30 & 100 & 820 & \pm 20 & $5 \cdot 00$ & $1 \cdot 0-2 \cdot 5$ \\
\hline & S1-20Sn & 20 & 150 & 1230 & \pm 30 & $3 \cdot 33$ & $0.09-0.43$ \\
\hline & $\mathrm{S} 1-20 \mathrm{Gr}$ & 20 & 150 & 1230 & \pm 30 & $3 \cdot 33$ & $3-7$ \\
\hline
\end{tabular}

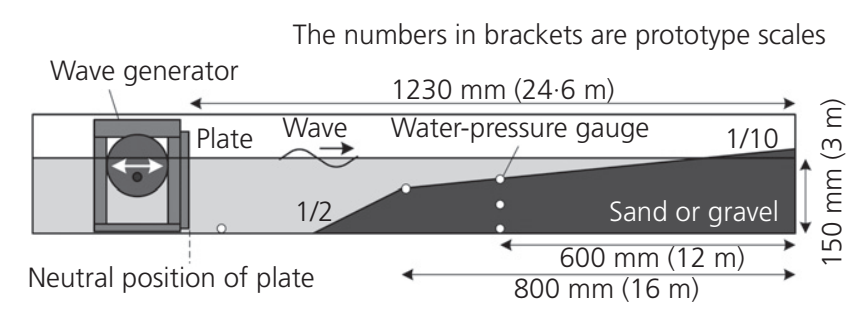

(a)

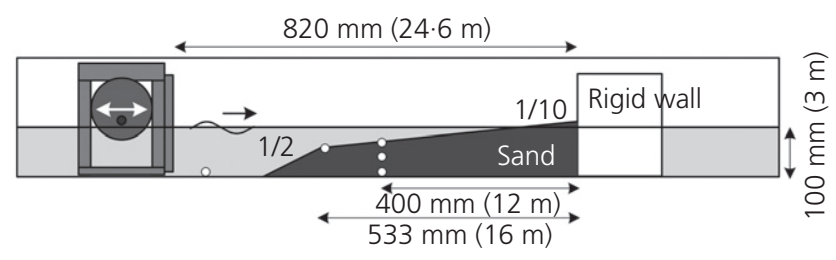

(b)

Figure 9. Schematic views of the models (series 51 ): (a) cases s1-20, S1-20Sn, S1-20Gr, (b) case S1-30

model, a centrifugal acceleration was added to the model. The other test conditions were the same as those in test series N2.

\subsection{Waveform}

The captured waveforms of cases S1-20 and S1-30 were compared to confirm their similarity. Figure 10 shows the waveforms observed with centrifugal accelerations of $20 \mathrm{~g}$ and $30 \mathrm{~g}$, and captured by each $1 / 4$ period. Picture sizes were adjusted to the same scale in order to compare them visually. The water surfaces were traced by broken lines in order to identify them easily. The waves broke and ran up on the seashore and coincided well at each point in time. Furthermore, several sand particles drifted around the wave-breaking point, wherein a strong current occurred. This phenomenon was observed in both cases.

In addition to the modelling of models test, fluid numerical analysis was carried out in order to simulate series S1 by using CADMAS-SURF. A numerical analysis was conducted on the prototype scale; the width of the mesh was set to 0.25 and $0.10 \mathrm{~m}$ in the horizontal and vertical direction, respectively. The piston-type wave-generator scheme was used to input the waves with a wave period of $6.0 \mathrm{~s}$ and wave height of $0.62 \mathrm{~m}$. Figure 11 presents the calculated waveform of each $1 / 4$ period. These waveforms corresponded to the results shown in Figure 10.

\subsection{Water pressure and flow velocity}

Figure 12 shows the variations of excess water pressures measured on and in the ground in series S1. Time scale is converted to the prototype. Figure 12(a) demonstrates the variations measured at the slope top on the ground. This figure includes the result calculated by numerical analysis. As shown in the figure, all experimental and calculated variations correspond approximately, despite the changes in centrifugal acceleration or ground material. The amplitude difference between the model tests and numerical analysis was approximately $-15-15 \%$.

Figures 12(b) and 12(c) show the variations of excess porewater pressures, measured in the ground, at a horizontal distance of $4 \mathrm{~m}$ from the slope top. The sensors were embedded at depths of $1 \cdot 1$ and $2 \cdot 2 \mathrm{~m}$. An increasing trend in excess porewater pressure was not observed in the figures. This indicated that accumulated pore-water pressure, due to cyclic loading, did not need to be considered. The figure also demonstrates that the values of cases S1-20 and S1-30 coincided well. Case S1-20Gr also had similar pore-water pressure. This might be due to the gravel of case S1-20Gr not being significantly different to the materials of cases S1-20 and S1-30. Conversely, these values were completely different to the values in case S1-20Sn, which did not satisfy the similarity law with respect to soil particle size. These results revealed the high reproducibility of pore-water pressure response, if similarity laws are adequately considered.

Figure 13 shows the flow velocity measured by two sensors at the horizontal distance of $4 \mathrm{~m}$ from the slope top on the ground, in the case of S1-20Gr. The figure also includes the result calculated by numerical analysis. Velocity towards the shore is positive. The measured velocity increased rapidly and then decreased, while negative velocity remained stable. The rapid increase and magnitude of velocity could be simulated by numerical analysis. In contrast, the rapid decrease could not be simulated. The flow velocity is known to be difficult to measure because the sensor disturbs the water flow; 
International Journal of Physical Modelling in Geotechnics Volume 19 Issue 3
Centrifuge modelling of breaking waves and seashore ground

Takahashi, Morikawa and Kashima

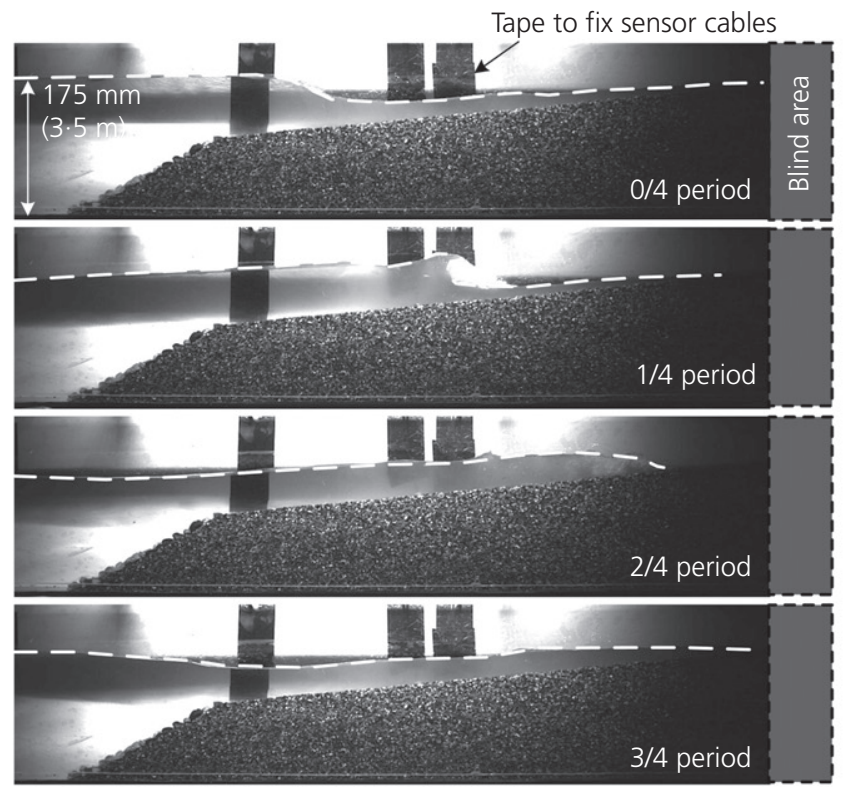

(a)
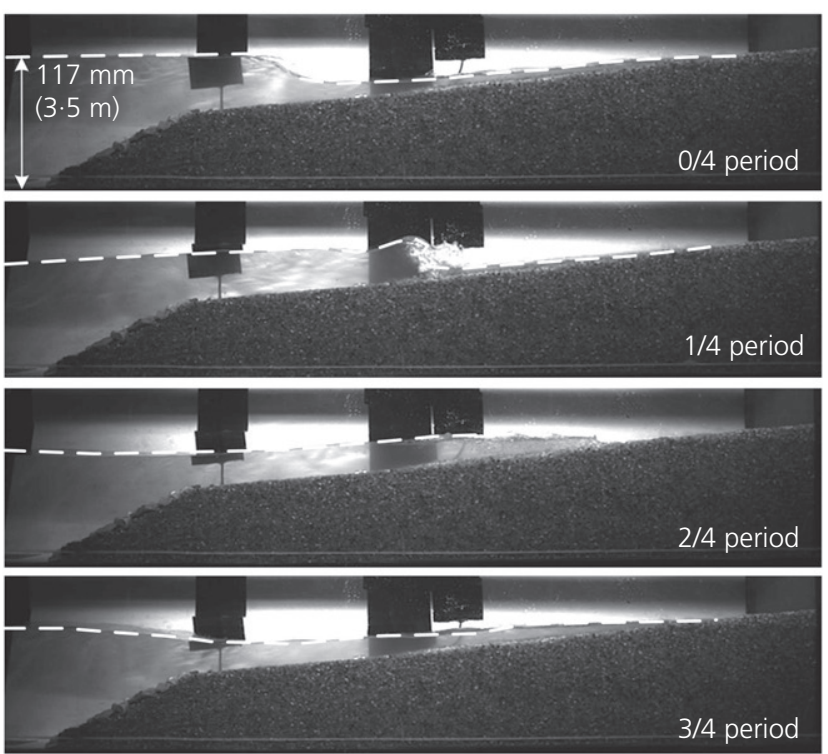

(b)

Figure 10. Waveforms observed in the tests (cases S1-20 and S1-30): (a) case S1-20 (under 20g), (b) case S1-30 (under 30 g)

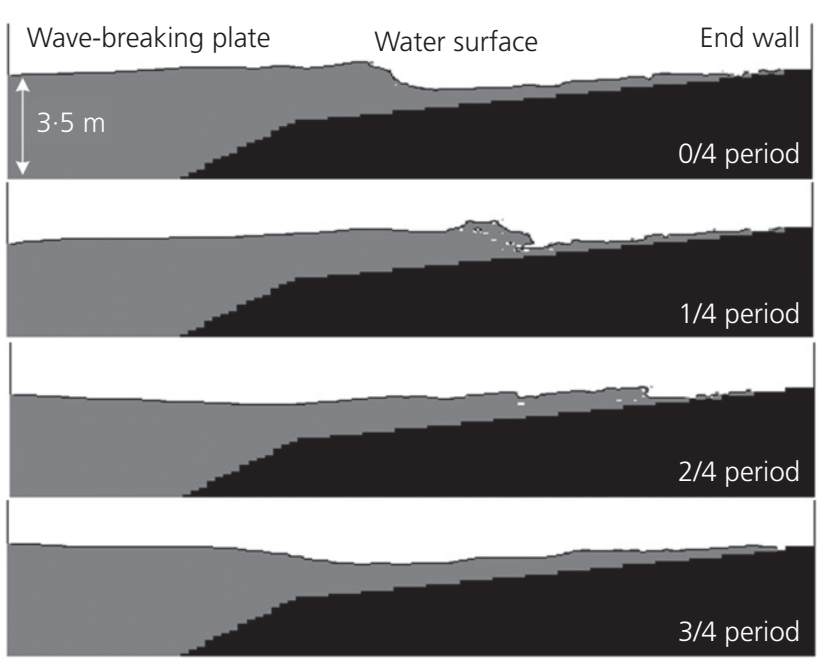

Figure 11. Calculated waveforms simulating series S1

therefore, a more sophisticated method should be adopted to measure velocity.

\subsection{Comparison with theoretical and empirical equations}

This section examines wave breaking in detail. Figure 14 presents the sequence pictures taken at each $1 / 8$ period, in the case of S1-20 and S1-30. As mentioned above, the wavebreaking characteristics, in these cases, were quite similar. The type of breaker appeared to be between plunging- and surgingtype breakers. This type of breaker often occurs in the case where the topography has a step on the foreshore. Since the ground used in the tests had a stage on the foreshore, the centrifuge model tests were consistent with experience regarding the type of breaker.

The wave height was compared to theoretical and empirical equations at each seashore point. On the shore, the waves steepen by wave shoaling under the effects of the bottom, and then break due to shallow water wave breaking in the surf zone. The wave height outside the surf zone, where the shallow water effect becomes dominant, can be estimated by the following equation, based on small-amplitude wave theory

$$
\text { 3. } \frac{H}{H_{0}}=\left\{\left(1+\frac{2 k h}{\sinh 2 k h}\right) \tanh k h\right\}^{-1 / 2}
$$

where $H_{0}$ is the deep-water wave height $(\mathrm{m}), k$ the wave number $(1 / \mathrm{m})$ and $h$ is the water depth $(\mathrm{m}) . H_{0}$ is the wave height measured in front of a wave generator divided by the shoaling coefficient $K_{\mathrm{s}}=1 \cdot 019 . k$ is given by the relation: $k=2 \pi / L$, where $L$ is the wave length given by the linear dispersion relation. On the other hand, the wave height for the 
Centrifuge modelling of breaking waves and seashore ground

Takahashi, Morikawa and Kashima

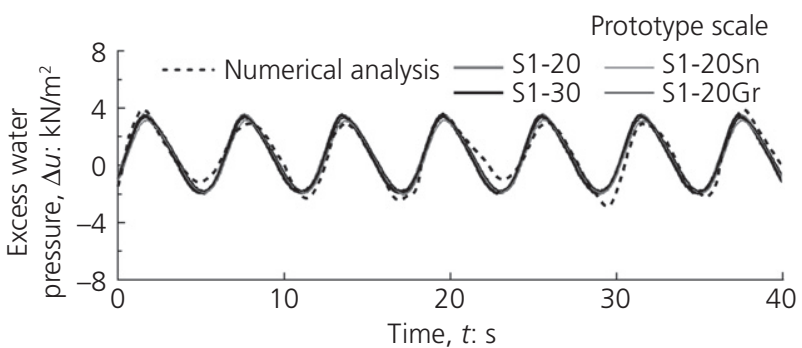

(a)

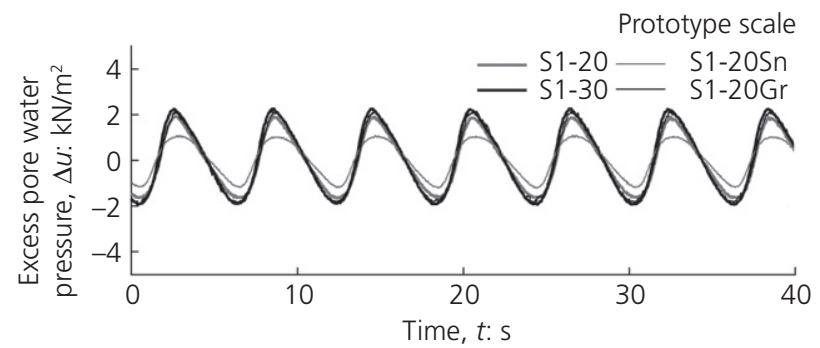

(b)

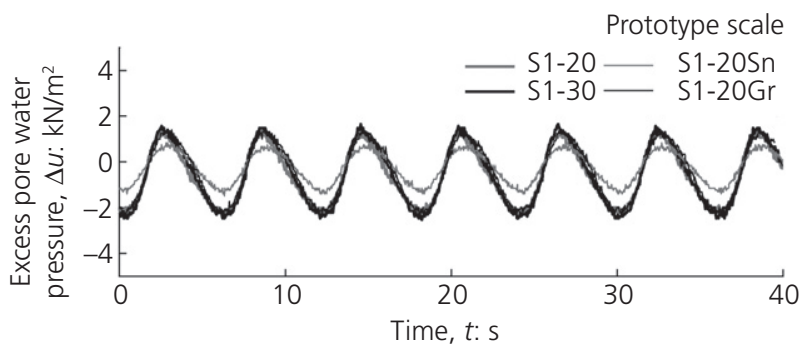

(c)

Figure 12. Experimental and calculated variations of water pressure (series S1): (a) ground surface (slope top), (b) G.L.-1.1 m ( $4 \mathrm{~m}$ from slope top on prototype scale), (c) G.L. $-2 \cdot 2 \mathrm{~m}$ (4 $\mathrm{m}$ from slope top on prototype scale)

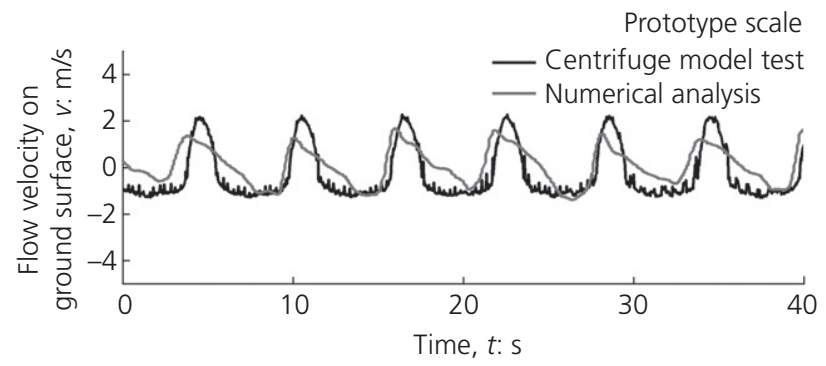

Figure 13. Experimental and calculated flow velocity (series S1)

periodic waves in the surf zone can be estimated by the following empirical equation proposed by Goda (2000)

4. $\frac{H}{L_{0}}=0 \cdot 17\left[1-\exp \left\{-1 \cdot 5 \frac{\pi h}{L_{0}}\left(1+15 \tan ^{4 / 3} \beta\right)\right\}\right]$

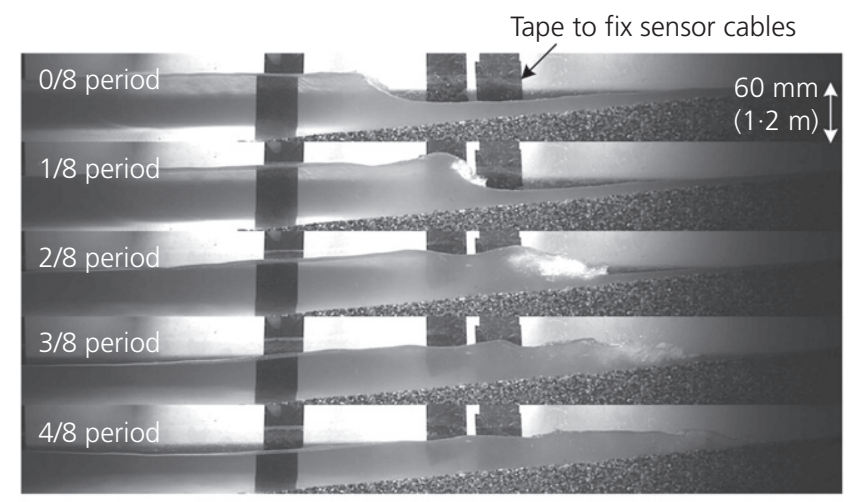

(a)

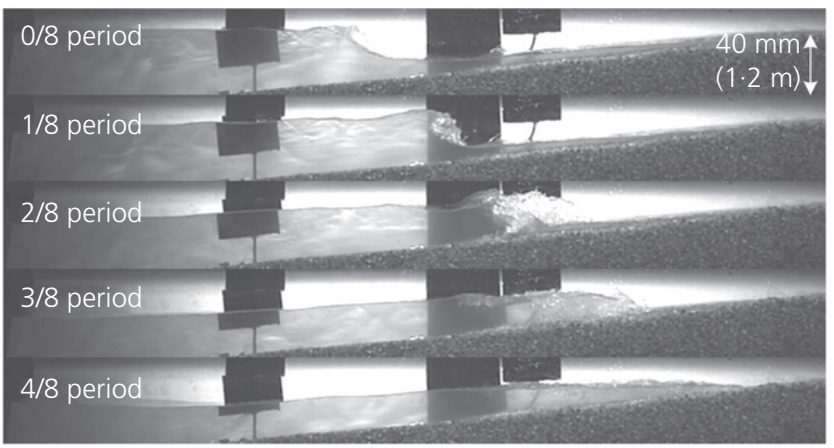

(b)

Figure 14. Sequence pictures showing wave breaking (cases S1-20 and S1-30): (a) case S1-20 (under 20g),

(b) case $\mathbf{5 1 - 3 0}$ (under $\mathbf{3 0 g}$ )

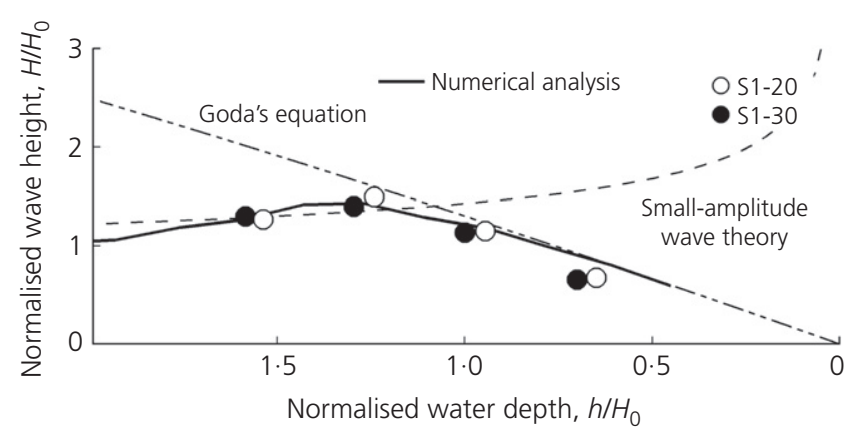

Figure 15. Wave height at each point (cases S1-20 and S1-30)

where $L_{0}$ is the deep-water wave length given by the following relation: $L_{0}=g T^{2} / 2 \pi$ and $\beta$ is the sea-bottom slope angle.

Figure 15 shows the relationship between the wave height and water depth of cases S1-20 and S1-30. Both the wave height and water depth were divided by $H_{0}$ in the case of S1-20 and S1-30. Figure 15 also includes the value obtained by 
International Journal of Physical Modelling in Geotechnics Volume 19 Issue 3
Centrifuge modelling of breaking waves

and seashore ground

Takahashi, Morikawa and Kashima

Table 4. List of model tests (series S2 and S3)

\begin{tabular}{cccccccc} 
Series & Case & $\begin{array}{c}\text { Centrifugal } \\
\text { acceleration: } \mathbf{g}\end{array}$ & $\begin{array}{c}\text { Water } \\
\text { depth: } \\
\mathbf{m m}\end{array}$ & $\begin{array}{c}\text { Longitudinal } \\
\text { length: } \mathbf{m m}\end{array}$ & $\begin{array}{c}\text { Displacement of } \\
\text { wave plate: } \mathbf{m m}\end{array}$ & $\begin{array}{c}\text { Frequency of } \\
\text { wave plate: Hz }\end{array}$ & $\begin{array}{c}\text { Average diameter } \\
\text { of soil particle: } \mathbf{m m}\end{array}$ \\
\hline S2 & S2-3 & 40 & 130 & 1230 & \pm 20 & 3 & $1 \cdot 7-4 \cdot 8$ \\
& S2-5 & 40 & 130 & 1230 & \pm 20 & 5 & $1 \cdot 7-4 \cdot 8$ \\
S3 & S3-3 & 40 & 130 & 1230 & \pm 40 & 3 & $1 \cdot 7-4 \cdot 8$ \\
& S3-5 & 40 & 130 & 1230 & \pm 40 & 5 & $1 \cdot 7-4 \cdot 8$
\end{tabular}

Equations 3 and 4 and the previously discussed numerical analysis. The experimental wave heights were obtained from the captured pictures. As shown in the figure, the normalised wave height in the cases of S1-20 and S1-30 increased to $1 \cdot 4-1 \cdot 5$ due to shoaling. Then, the normalised wave height in the cases of S1-20 and S1-30 decreased due to breaking. The trend changed from increasing to decreasing at approximately the normalised water depth of $1 \cdot 2-1 \cdot 3$. The lines obtained by the theoretical and empirical equations almost coincided with the wave heights of the model tests. In the numerical analysis, the wave height trend changed from increasing to decreasing at the normalised water depth of $1 \cdot 3-1 \cdot 4$. This also agreed with the value measured in the model tests. Thus, the centrifuge model test could simulate the change of wave height due to shoaling and breaking.

\section{Response of ground pore-water pressure}

\subsection{Model test conditions}

In the above sections, the efficacy of the centrifuge model test was verified. In this section, the properties of pore-water pressure were investigated by using test series S2 and S3, which included a large stage of seashore ground. Four test cases were carried out by changing the wave height and wave period. Table 4 and Figure 16 show the conditions and schematic view of these cases, respectively. The displacement of the wave-

The numbers in brackets are prototype scales
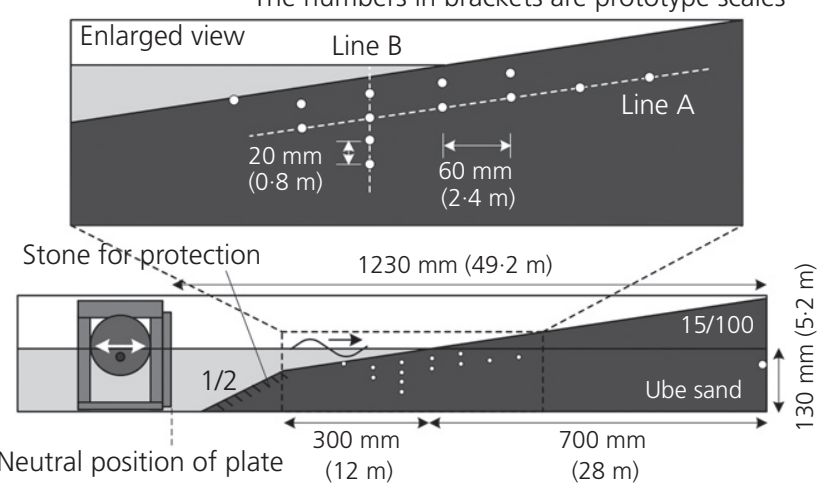

Figure 16. Schematic view of the model (series S2 and S3) making plate was changed in series S2 and S3. Each series had two cases employing different wave frequencies. The ground material was number $1 \mathrm{~A}$ Ube sand. This was silica sand excavated in the Yamaguchi Prefecture in Japan, with a particle diameter of approximately $1 \cdot 7-4.8 \mathrm{~mm}$. This diameter was sufficiently large to cause turbulence to the flow in the void. Additionally, the tests satisfied the similarity law, which is expressed as law 1 shown in Table 1 . The ground was manufactured by soft tapping layer by layer and the slope was protected by rubble stones. Many water-pressure gauges were embedded on lines $\mathrm{A}$ and $\mathrm{B}$ in order to measure the distribution of pore-water pressure (see Figure 16). The rest of the test conditions were the same as those of the test series S1.

\subsection{Test results}

Figure 17 shows the maximum and minimum excess porewater pressure measured in series S2 and S3. Water pressure on the ground surface was estimated by wave height. The positions of sensors can be noted in Figure 16. Figures 17(a) and 17 (b) demonstrate the horizontal distribution at a depth of $1.6 \mathrm{~m}$ (line A) and the vertical distribution at $2.4 \mathrm{~m}$ away from the shoreline (line B), respectively. The horizontal axis of Figure 17(a) represents the distance from the shoreline. Solid and dashed lines refer to maximum and minimum values, respectively. Little phase lag was measured in the vertical distribution, and Figure 17(b) shows almost the same distribution, the peak times of surge and backwash.

This figure shows that, in every case, the variations were not symmetrical with respect to the zero-axis. Excess pore-water pressure inclined towards the positive. This was because waves set-up onto the seashore, due to wave breaking; as a result, the tide level moved upward. Increasing the wave height and/or the wave frequency led to an increase in the significance of this phenomenon. Furthermore, the excess pore-water pressure initially increased and subsequently decreased towards the shore. This could have also been induced in response to wave shoaling and breaking, even in the ground.

The vertical distribution shown in Figure 17(b) indicates that, due to the wave set-up, the variations of excess pore-water pressure were inclined towards the positive values in the figure. 
International Journal of Physical Modelling in Geotechnics Volume 19 Issue 3
Centrifuge modelling of breaking waves and seashore ground

Takahashi, Morikawa and Kashima

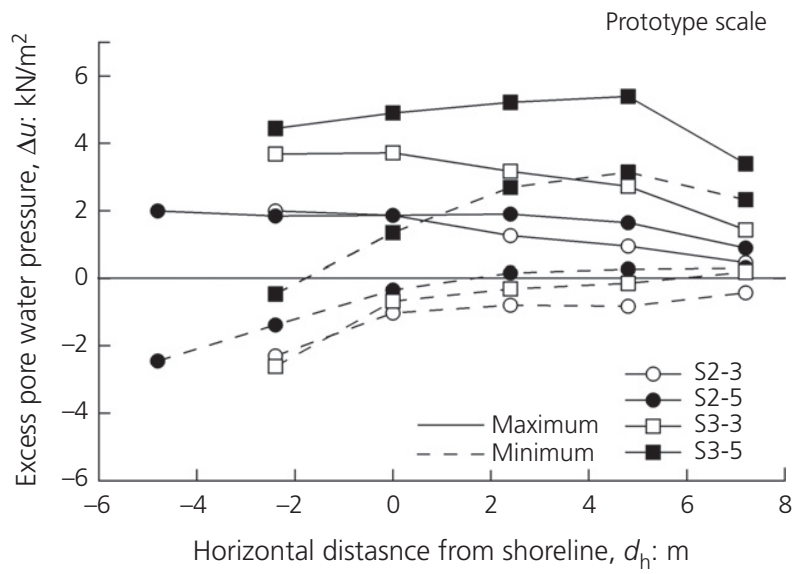

(a)

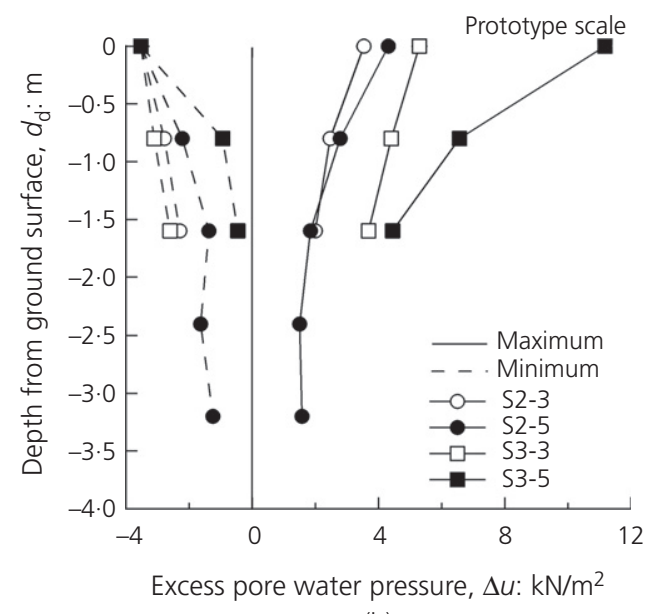

(b)

Figure 17. Variations of pore-water pressure in the ground (series S2 and S3): (a) horizontal distribution (obtained on line A in Figure 16), (b) vertical distribution (obtained on line B in Figure 16)

Additionally, in each case, the variations were small in the deep area. This tendency was strong when the wave height and/or the wave frequency increased. By considering the state of backwash, the small variations in the deep area generated an upward seepage force since, at that time, the excess porewater pressure in the shallow area was smaller than that in the deep area. This upward seepage force would lift up soil particles and reduce seashore ground stability. Thus, increasing the wave height and/or wave frequency induced small variations of excess pore-water pressure in the deep area and the seepage force.

\section{Conclusions}

This study demonstrated the efficacy of the centrifuge modelling of breaking wind waves and seashore ground response on pore-water pressure. First, the study showed the similarity laws including fluid behaviours. In addition, a new wave generator was developed, with consideration to the limited capacity and area of the centrifuge platform. Second, techniques such as the modelling of models method, numerical analysis and theoretical and empirical equations were employed in examining the reproducibility of breaking waves and ground responses. The prototypes modelled by several models, at different scales, corresponded approximately. The test results were similar to those of numerical analysis and the theoretical and empirical equations. These results verified that centrifuge modelling displayed efficacy with respect to waveforms, wave height change due to shoaling and breaking, and water pressure on and in the ground. Finally, this paper discussed the variation properties of pore-water pressure in the ground. The excess porewater pressure in the seashore ground inclined towards the positive due to the wave set-up induced by wave breaking. Based on the vertical distribution of excess pore-water pressure, increasing the wave height and/or the wave frequency induced a seepage force. This could decrease the stability of the seashore ground. In the future, the ground behaviour under breaking waves will be discussed in more detail by using the method described in this paper.

\section{Acknowledgement}

This study was supported by JSPS Kakenhi grant number JP25820218 and JP17H03308. The authors gratefully acknowledge this financial support. In addition, the authors thank Satoshi Saito of Geodesign Co for his help in the centrifuge model tests.

\section{REFERENCES}

Andersen TL and Burcharth HF (2010) A new formula for front slope recession of berm breakwaters. Coastal Engineering 57(4): 359-374.

Baba S, Miyake M, Tsurugasaki K and Kim H (2002) Development of wave generation system in a drum centrifuge. Proceedings of the International Conference on Physical Modelling in Geotechnics, St. John's, NL, Canada. Balkema, Lisse, the Netherlands, pp. 265-270.

Bakhtyar R, Barry DA, Li L, Jeng DS and Yeganeh-Bakhtiary A (2009) Modeling sediment transport in the swash zone: a review. Ocean Engineering 36(9-10): 767-783.

Bezuijen A and Steedman RS (2010) Scaling of hydraulic processes. Proceedings of the International Conference on Physical Modelling in Geotechnics, Zurich, Switzerland. CRC Press, Leiden, the Netherlands, pp. 93-98.

CDIT (Coastal Development Institute of Technology) (2001) Research and Development of Numerical Wave Flume. CDIT-Library, Tokyo, Japan (in Japanese).

Chang SC, Lin JG, Chien LK and Chiu YF (2007) An experimental study on non-linear progressive wave-induced dynamic stresses in seabed. Ocean Engineering 34(17-18): 2311-2329.

Chappell J, Eliot IG, Bradshaw MP and Lonsdale E (1979) Experimental control of beach face dynamics by watertable pumping. Engineering Geology 14(1): 29-41.

Cheng C (2003) Sand Bed Response under Wave Loadings Using a Centrifuge. Master thesis, Engineering Department of Civil 
International Journal of Physical Modelling in Geotechnics Volume 19 Issue 3
Centrifuge modelling of breaking waves

and seashore ground

Takahashi, Morikawa and Kashima
Engineering, National University of Singapore, Singapore, Singapore.

Davis GA, Hanslow DJ, Hibbert K and Nielsen P (1992) Gravity drainage: a new method of beach stabilisation through drainage of the watertable. Proceedings of the International Conference on Coastal Engineering, Venice, Italy. ASCE, Reston, VA, USA, pp. 1129-1141.

Elfrink B and Baldock T (2002) Hydrodynamics and sediment transport in the swash zone: a review and perspectives. Coastal Engineering 45(3-4): 149-167.

Gao FP and Randolph MF (2005) Progressive ocean wave modelling in drum centrifuge. Proceedings of the International Symposium on Frontiers in Offshore Geotechnics (IS-FOG 2005), Perth, Australia. Balkema, Leiden, the Netherlands, pp. 583-588.

Goda Y (2000) Random Seas and Design of Maritime Structures, 2nd edn. World Scientific, Singapore, Singapore.

Grant US (1948) Influence of the water table on beach aggradation and degradation. Journal of Marine Research 7(3): 655-660.

Hall KR and Kao JS (1991) The influence of armour stone gradation on dynamically stable breakwaters. Coastal Engineering 15(4): 333-346.

Hanzawa M, Matsumoto A and Tanaka H (2012) Applicability of CADMAS-SURF to evaluate detached breakwater effects on solitary tsunami wave reduction. Earth, Planets and Space 64(10): 955-964.

Hirt CW and Nichols BD (1981) Volume of fluid (VOF) method for the dynamics of free boundaries. Journal of Computational Physics 39(1): 201-225.

Kitazume M and Miyajima S (1995) Development of PHRI Mark II Geotechnical Centrifuge. Port and Harbour Research Institute, Yokosuka, Japan. Technical note no. 812.

Machemehl JL, French TJ and Huang NE (1975) New method for beach erosion control. Civil Engineering in the Oceans. ASCE, Reston, VA, USA, pp. 142-160.

Madsen OS (1978) Wave-induced pore pressures and effective stresses in a porous bed. Géotechnique 28(4): 377-393, http://dx.doi.org/ 10.1680/geot.1978.28.4.377.

Phillips R and Sekiguchi H (1992) Generation of water wave trains in drum centrifuge. Proceedings of the International Symposium on Technology in Ocean Engineering (Techno-Ocean'92), Yokohama, Japan. JIMSTEF, Tokyo, Japan, vol. 1, pp. 29-34.
Phung DH, Tanimoto K and Vu TC (2004) Numerical simulation of breaking waves using a two-phase flow model. Applied Mathematical Modelling 28(11): 983-1005.

Sakuraba M, Sakakiyama T, Arikawa T et al. (2008) An investigation for applicability of wave run-up by CADMAS-SURF. Proceedings of Civil Engineering in the Ocean, Kurashiki, Japan. JSCE, Tokyo, Japan, vol. 24, pp. 867-872 (in Japanese).

Sassa S and Sekiguchi H (1999) Wave-induced liquefaction of beds of sand in a centrifuge. Géotechnique 49(5): 621-638, http:// dx.doi.org/10.1680/geot.1999.49.5.621.

Seed HB and Rahman MS (1978) Wave-induced pore pressure in relation to ocean floor stability of cohesionless soils. Marine Geotechnology 3(2): 123-150.

Sekiguchi H and Phillips R (1991) Generation of water waves in a drum centrifuge. Proceedings of the International Conference CENTRIFUGE 91, Boulder, CO, USA. Balkema, Rotterdam, the Netherlands, pp. 343-350.

Sekiguchi H, Kita K and Okamoto O (1995) Response of poro-elastoplastic beds to standing waves. Soils and Foundations 35(3): 31-42.

Takahashi H, Kitazume M, Ishibashi S and Yamawaki S (2006) Evaluating the saturation of model ground by P-wave velocity and modelling of models for a liquefaction study. International Journal of Physical Modelling in Geotechnics 6(1): 13-25, http://dx.doi.org/ 10.1680/ijpmg.2006.060102.

Takahashi H, Ogawa K, Hayano K, Morikawa $Y$ and Ninomiya $Y$ (2010) Centrifuge model test on wave force resistance of artificial seashore reclaimed by granular treated soil. Annual Journal of Civil Engineering in the Ocean 26: 687-692 (in Japanese).

Takahashi H, Sassa S, Morikawa Y, Takano D and Maruyama K (2014) Stability of caisson-type breakwater foundation under tsunami-induced seepage. Soils and Foundations 54(4): 789-805.

Tayler RN (1995) Geotechnical Centrifuge Technology. Chapman \& Hall, London, UK

Tsai CP and Lee TL (1995) Standing wave induced pore pressures in a porous seabed. Ocean Engineering 22(6): 505-517.

Van Der Meer JW (1987) Stability of breakwater armour layers - design formulae. Coastal Engineering 11(3): 219-239.

\section{How can you contribute?}

To discuss this paper, please email up to 500 words to the editor at journals@ice.org.uk. Your contribution will be forwarded to the author(s) for a reply and, if considered appropriate by the editorial board, it will be published as discussion in a future issue of the journal.

International Journal of Physical Modelling in Geotechnics relies entirely on contributions from the civil engineering profession (and allied disciplines). Information about how to submit your paper online is available at www. icevirtuallibrary.com/page/authors, where you will also find detailed author guidelines. 